\title{
Hybrid MCDA Methods to Integrate Multiple Ecosystem Services in Forest Management Planning: A Critical Review
}

Britta Uhde ${ }^{1}$, W. Andreas Hahn ${ }^{1}$, Verena C. Griess ${ }^{2}$, Thomas Knoke ${ }^{1}$

Britta Uhde

uhde@forst.wzw.tum.de

W. Andreas Hahn

andreas.hahn@mytum.de

Verena C. Griess

verena.griess@ubc.ca

Thomas Knoke

knoke@forst.wzw.tum.de

1 Institute of Forest Management, Department of Ecology and Ecosystem Management, Center of Life and Food Sciences

Weihenstephan, Technische Universitat Munich, Hans-Carl-von-Carlowitz-Platz 2, 85354 Freising, Germany 2 Department of Forest Resources Management, Faculty of Forestry, University of British Columbia, Forest Sciences Center, 2211-2424 Main Mall, Vancouver, BC V6T1Z4, Canada

\section{Keywords}

Ecosystem services, Trade-offs, Forest management planning, Stakeholder participation, Uncertainty, Quantitative optimization, Multiple criteria 


\section{Abstract}

Multi-criteria decision analysis (MCDA) is a decision aid frequently used in the field of forest management planning. It includes the evaluation of multiple criteria such as the production of timber and non-timber forest products and tangible as well as intangible values of ecosystem services (ES). Hence, it is beneficial compared to those methods that take a purely financial perspective. Accordingly, MCDA methods are increasingly popular in the wide field of sustainability assessment. Hybrid approaches allow aggregating MCDA and, potentially, other decision-making techniques to make use of their individual benefits and leading to a more holistic view of the actual consequences that come with certain decisions. This review is providing a comprehensive overview of hybrid approaches that are used in forest management planning. Today, the scientific world is facing increasing challenges regarding the evaluation of ES and the trade-offs between them, for example between provisioning and regulating services. As the preferences of multiple stakeholders are essential to improve the decision process in multi-purpose forestry, participatory and hybrid approaches turn out to be of particular importance. Accordingly, hybrid methods show great potential for becoming most relevant in future decision making. Based on the review presented here, the development of models for the use in planning processes should focus on participatory modeling and the consideration of uncertainty regarding available information.

\section{Introduction}

The process of decision making in forest management planning today must allow for the consideration of multiple, and often competing objectives. Decision outcomes must simultaneously balance ecological, social, and economic interests within a temporal and spatial matrix (Hahn and Knoke 2010). Thus, decision making on a supra-individual, societal level must consider a diversity of objectives, which might conflict with one another.

Multi-criteria decision analysis (MCDA) is a tool that has been developed to help solve such complex problems (Mendoza et al. 1999). MCDA methods have often been used to define criteria and indicators for the promotion of sustainable development and resource utilization (Mendoza and Prabhu 2000; Wolfslehner et al. 2005), besides they can consider 
the non-market values of ecosystem services (ES). ES include "provisioning services such as food, water, timber, fiber, and genetic resources; regulating services such as the regulation of climate, floods, disease, and water quality as well as waste treatment; cultural services such as recreation, esthetic enjoyment, and spiritual fulfillment; and supporting services such as soil formation, pollination, and nutrient cycling" (MEA 2005, p. 39).

Using MCDA, explicit trade-offs between multiple ES can be evaluated and quantified to give a better understanding of trade-off relationships between different objectives (Sanon $e t$ al. 2012), provided that the alternatives considered have actually included the "best" options. Therefore, MCDA is an appropriate approach to use in sustainability assessment (Boggia and Cortina 2010; Wolfslehner et al. 2012). MCDA methods allow for the evaluation and prioritization of management alternatives, even when no consensus can be found. Indeed, consensus is often hard to achieve under heterogeneous objectives (Mendoza et al. 1999). MCDA methods are best applied in situations that require a strong integration of theory and practice (Belton and Stewart 2002). This integration can be realized with the use of hybrid methods that apply MCDA with, potentially, different other decision-making methods such as mathematical programming-based optimization. A combination of methods is beneficial because different areas of research can complement each other (Feizizadeh and Blaschke 2013). The application of analytical, spatial planning, or group decision-making (GDM) methods can evaluate and analyze ES in different ways, and therefore improve the calculation of trade-offs between them. To this end, the further development of hybrid methods has been recommended by various authors (Ananda and Herath 2009; Diaz-Balteiro and Romero 2008; Kangas and Kangas 2005; Mendoza and Martins 2006).

Our review paper focuses on forest management problems that demand analytic evaluation as well as the consideration of multiple ES. The definition of ES is expansive, capturing provisioning, regulating, cultural, and supporting services (see above). In general, every hybrid method can consider ES, but certain techniques can be more appropriate for specific kinds of ES. Provisioning and cultural services, for example, are more tangible to manage and could, for example, be considered with the application of MCDA and optimization techniques. Regulating and supporting services, on the other hand, can be difficult to quantify in practice and need to receive careful attention. A stakeholder analysis that incorporates the preferences of multiple participants is therefore very valuable for the evaluation of ES, but 
MCDA must then be combined with GDM. Also the use of MCDA and spatial analysis can consider regulating and supporting services with the designation of conservation and management areas. Also the ecosystem itself is an expansive domain. Willis (1997) summarized an ecosystem to be "a unit comprising a community (or communities) of organisms and their physical and chemical environment, at any scale, desirably specified, in which there are continuous fluxes of matter and energy in an interactive open system'". This definition implies conceptually that many factors have an influence on these ecosystems and may alter them over time. Therefore, possible changes need to be determined to adjust planning methods. A current example is the climate change and its possible effect on forest ecosystems.

There are already a great number of research articles and scientific reviews that cover the topic of MCDA in the field of forest management planning. However, recent developments on hybrid methods or the important aspects of trade-offs between various ES and how to address uncertainty are rare. The current review paper thus builds on an overview of hybrid methods which have been applied in forest management planning. The specific objectives are to identify limitations and to elaborate on recent developments of hybrid approaches for decision making in planning situations. We will then evaluate the capacity of these methods to account for uncertainty, while considering both ecological and economic issues, in order to promote sustainable resource utilization (Hahn and Knoke 2010). The integration of participation, uncertainty, and multiple ES into the planning process is also part of this study. In contrast to existing reviews (see Ananda and Herath 2009; Diaz-Balteiro and Romero 2008; Herva and Roca 2013; Kangas and Kangas 2005; Mendoza and Martins 2006; Triantaphyllou 2000; Velasquez and Hester 2013), the emphasis of our review paper is laid on the use of hybrid methods. How can hybrid methods consider participation, trade-offs between ES and integrate uncertainties?

The outline is as follows: In "Hybrid methods for improving the decision making process in forest management planning', section, we review the application of hybrid methods referring to examples in the field of forest management planning. "Overview of classical multi-criteria decision approaches" section provides a brief overview of literature with examples on the use of MCDA, while "Challenges and limitation of multi-criteria decision analysis" section 
covers the challenges and limitations of MCDA methods. A summary with suggestions of methodological improvements is provided in "Methodological improvements" section.

\section{Hybrid Methods for Improving the Decision Making Process in Forest Management Planning}

Decision problems and processes in natural resource management vary considerably. To best address different problems and stages in the decision process, the appropriate method has to be applied. Hybrid methods can be defined as the aggregation of MCDA and, potentially, other decision-making techniques. By this means, different features of methods can be integrated in the same decision process. One method, for example, could provide the framework for the problem structuring, whereas a second method could be integrated to work as a decision support tool (Kangas et al. 2001b). Hybrid methods are favorable in face of complex problems with various stakeholders, objectives, and long-term consequences, and aim at merging advantages of methods that operate in different ways (Diaz-Balteiro et al. 2009b; Kangas et al. 2008).

Hybrid methods can be combinations of quantitative and qualitative methods (Myllyviita et al. 2011). Qualitative methods (interviews, voting, etc.) can support problem structuring, compile preliminary definitions of goals (Pykalainen et al. 2007) and improve the learning process, and the understanding of stakeholders (Hjortsø 2004; Khadka et al. 2013), whereas quantitative methods (e.g., MCDA and mathematical programming-based optimization) help evaluating decision alternatives using numerical information (Myllyviita et al. 2011). Up to now, just a few examples of the combination of qualitative and quantitative methods exist (Myllyviita et al. 2011; Pykalainen et al. 2007). Other possibilities of hybrid methods are combinations of quantitative methods among one another. MCDA, for example, can be used to develop a management plan that responds to the preferences of stakeholders that are involved in the decision process. Within a hybrid method, MCDA can integrate these subjective preferences into the optimization problem (Kangas and Kangas 2005) to obtain information for the decision-making process. The comparison of alternatives and the decision making is subsequently carried out by the optimization tool. Optimization methods have a long tradition in forest management planning. Different management scenarios can arise during the optimization process by gradual incorporation of new management options such as 
set-asides, near-natural management, minimum rotation periods, and the energetic use of biomass. Hybrid methods can amalgamate optimization models with MCDA (Wolfslehner and Seidl 2010) to gain a more holistic view on the consequences of a decision. Because it maximizes and minimizes objectives, the mathematical programming based optimization technique is useful for the calculation of a management plan that contains the optimal harvest strategy. Benefits of hybrid methods are significant in situations of uncertainty with conflicting goals among different stakeholders (Belton and Stewart 2002). Figure 1 illustrates the application of a hybrid method. Applying different methods to the same process can improve the ease of use for the decision makers because it simplifies the evaluation of planning results. In the following sections, different applications of hybrid methods that are most often used for forest management decisions will be discussed, namely, (1) MCDA and quantitative optimization, (2) Hybrid methods for spatial decision problems, and (3) Hybrid approaches based on participatory or strategic planning. Particularly, we want to address the occurrence of hybrid methods that either combine MCDA with quantitative methods ("MCDA and quantitative optimization", "Hybrid methods for spatial decision problems", sections) or with qualitative methods ("Hybrid approaches based on participatory or strategic planning', section). Within these subsections and for every type of combination, references are arranged by dates to show the developmental trajectory of hybrid methods. By nature, the review is not exhaustive but the choice of applications reflects the research up till now in the field of hybrid methods in forest management planning. An overview of publications considering hybrid methods in forest management is given in Table 1. Bibliographic databases such as the Web of Knowledge were used for the literature review of MCDA and hybrid approaches presented here. The literature search was, inter alia, based on following keywords: MCDA, forest management, forest planning, optimization, stakeholder participation, uncertainty, ES, and trade-offs. While classic textbooks were also used, the literature search was mainly focused on peer-reviewed articles published in international journals covering the topics of MCDA and hybrid methods in forest management. 


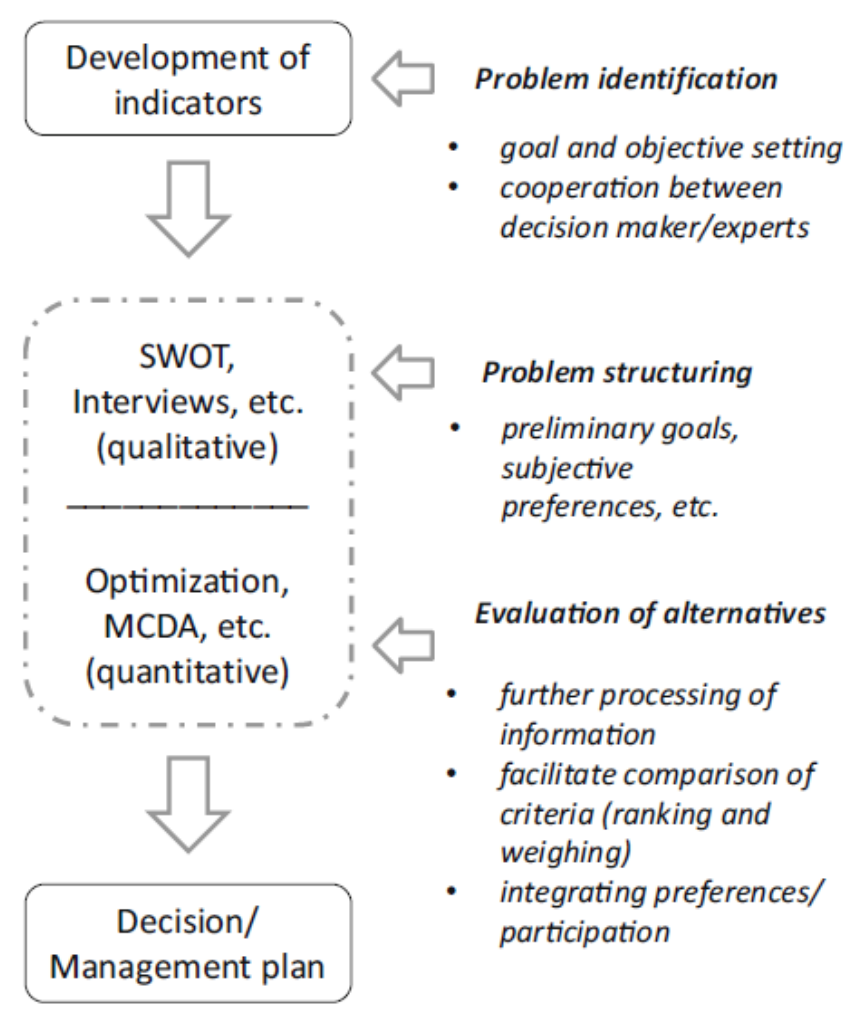

Fig. 1 Schematic example for an application of a hybrid method in a planning process

\section{MCDA and Quantitative Optimization}

A forest may consist of a multitude of forest stands which are treated in different ways at different points in time (Wolfslehner and Seidl 2010). The process of forest planning is complex, as it occurs at different spatial and temporal scales, affecting several stakeholders.

The first application of a hybrid method in forest management has been a combination of heuristic optimization and MCDA. Pukkala and Kangas (1993) as well as Kangas (1996) integrated the AHP into the HERO heuristic method. In this approach, treatment schedules were simulated for one planning period. The authors used the heuristic optimization method HERO to compile the optimal treatment schedules. HERO was used for the estimation and maximization of the utility function. The formulation of the optimization problem was carried out by the help of the analytical hierarchy process (AHP); in particular, the partial utility function and the weights of the objectives were estimated. 
Table 1 Overview of publications considering hybrid methods in forest management according to the type of combination indicating the methods applied, their characteristics, and whether they consider stakeholder participation or treatments of uncertainty

\begin{tabular}{|c|c|c|c|c|}
\hline \multirow[t]{2}{*}{ Methods applied } & \multirow[t]{2}{*}{ Characteristics } & \multicolumn{2}{|c|}{$\begin{array}{l}\text { Consideration } \\
\text { of participation } \\
\text { (a) and } \\
\text { uncertainty (b) }\end{array}$} & \multirow[t]{2}{*}{ Author $(s)$} \\
\hline & & a & $\mathrm{b}$ & \\
\hline \multicolumn{5}{|l|}{ MCDA and quantitative optimization } \\
\hline HERO, AHP & Integrating preferences into heuristic optimization & $\mathrm{X}$ & $\mathrm{X}$ & (Pukkala and Kangas 1993) \\
\hline HERO, AHP & Integrating preferences into heuristic optimization & $\mathrm{x}$ & $\mathrm{x}$ & (Kangas 1996) \\
\hline HERO, AHP, GIS, Bayesian analysis & $\begin{array}{l}\text { Producing alternative forest plans with respect to } \\
\text { stakeholder preferences and ecological values }\end{array}$ & $\mathrm{x}$ & $\mathrm{x}$ & (Kangas et al. 2000) \\
\hline $\begin{array}{l}\text { Forest growth model FORMIND, } \\
\text { MAVT }\end{array}$ & $\begin{array}{l}\text { Simulation of logging scenarios, investigating } \\
\text { long-term impacts }\end{array}$ & & & (Huth et al. 2004) \\
\hline $\begin{array}{l}\text { Forest growth model FORMIND, } \\
\text { PROMETHEE }\end{array}$ & $\begin{array}{l}\text { Simulation of logging scenarios, investigating } \\
\text { long-term impacts }\end{array}$ & & $\mathrm{X}$ & (Huth et al. 2005) \\
\hline $\begin{array}{l}\text { Additive utility program, DSD v1.1 } \\
\text { (decision support Dobrova) }\end{array}$ & $\begin{array}{l}\text { Analysis of silvicultural treatments, computer- } \\
\text { based analytical support }\end{array}$ & & $\mathrm{X}$ & (Lexer et al. 2005) \\
\hline AHP, GP & $\begin{array}{l}\text { Aggregation of individual preferences and } \\
\text { different types of multiple criteria }\end{array}$ & $\mathrm{X}$ & $\mathrm{X}$ & (Diaz-Balteiro et al. 2009b) \\
\hline AHP, forst planning tool PlanWise & $\begin{array}{l}\text { Analysis of silvicultural treatments, computer- } \\
\text { based analytical support }\end{array}$ & $\mathrm{X}$ & $\mathrm{X}$ & (Korosuo et al. 2011) \\
\hline $\begin{array}{l}\text { Heureka decision support system, } \\
\text { SMART }\end{array}$ & Promotion of ecological and social objectives & & & (Nordström et al. 2013) \\
\hline \multicolumn{5}{|l|}{ MCDA and spatial planning } \\
\hline Visualization, MCDA & $\begin{array}{l}\text { Presenting forest management scenarios with 3D } \\
\text { landscape visualization and integrating public } \\
\text { participation }\end{array}$ & $\mathrm{X}$ & & (Sheppard and Meitner 2005) \\
\hline GIS, fuzzy AHP & $\begin{array}{l}\text { Designing of forest fire risk zones on knowledge- } \\
\text { based information }\end{array}$ & $\mathrm{X}$ & $\mathrm{X}$ & (Sharma et al. 2012) \\
\hline GIS, AHP, interviews & $\begin{array}{l}\text { Integrating participatory processes with GIS and } \\
\text { AHP }\end{array}$ & $\mathrm{X}$ & $\mathrm{X}$ & (Zhang et al. 2013) \\
\hline GIS, ELECTRE TRI & $\begin{array}{l}\text { Creating forest stand maps with spatial } \\
\text { interpolation and MCDA }\end{array}$ & & & (Destan et al. 2013) \\
\hline GIS, MCDA & $\begin{array}{l}\text { Integrating stakeholder preferences and GIS-based } \\
\text { MCDA to identify restoration priorities }\end{array}$ & $\mathrm{X}$ & $\mathrm{X}$ & (Uribe et al. 2014) \\
\hline \multicolumn{5}{|l|}{ MCDA and participatory planning } \\
\hline $\begin{array}{l}\text { Voting methods, interactive utility } \\
\text { analysis (IUA), multi-criteria } \\
\text { approval }\end{array}$ & $\begin{array}{l}\text { Analysis of feedback from stakeholders, } \\
\text { promoting the participants' learning process }\end{array}$ & $\mathrm{X}$ & & (Pykäläinen et al. 2007) \\
\hline AHP, stakeholder analysis, interviews & $\begin{array}{l}\text { Combination of forest data with information from } \\
\text { interviews to create management zones }\end{array}$ & $\mathrm{X}$ & $\mathrm{X}$ & (Nordström et al. 2010) \\
\hline SWOT, AHP & $\begin{array}{l}\text { Development of a strategy with the analytical } \\
\text { support of the AHP }\end{array}$ & $\mathrm{X}$ & $\mathrm{X}$ & $\begin{array}{l}\text { (Groselj and Zadnik Stirn } \\
\text { 2013) }\end{array}$ \\
\hline \multicolumn{5}{|l|}{ MCDA and strategic planning } \\
\hline SWOT, AHP & $\begin{array}{l}\text { Development of a strategy with the analytical } \\
\text { support of the AHP }\end{array}$ & $\mathrm{X}$ & $\mathrm{X}$ & (Kurttila et al. 2000) \\
\hline SWOT, AHP & $\begin{array}{l}\text { Development of a strategy with the analytical } \\
\text { support of the AHP }\end{array}$ & $\mathrm{X}$ & $\mathrm{X}$ & (Kangas et al. 2001c) \\
\hline
\end{tabular}

The authors applied this approach of heuristic optimization and AHP to the forest management in Pitkajarvi state forest in Finland considering the participation of several interest groups. The overall utility that was estimated using the AHP was then maximized 
through HERO optimization. In this way, optimal solutions of approximately 1000 treatment schedules could be defined (Kangas 1996). In a further study, Kangas et al. (2000) combined HERO with the AHP, geographic information system (GIS), and Bayesian analysis to integrate expert knowledge and uncertainty into the decision process and generate forest alternatives. GIS was used to analyze the requirements for different compartments to help establishing adjusted management plans. The technique of preference analysis in combination with heuristic optimization has the strength to enlighten a complex decision process to the decision makers and to the participants. The weakness of this case study is the missing accuracy of forest dynamics and long-term planning.

Discrete MCDA methods can also be combined with other quantitative optimization tools. Several studies applied MCDA methods within forest management models to integrate ES and preferences into the decision process. Huth et al. (2004) used multi-criteria evaluation to generate logging scenarios in the rain forests of Malaysia in order to analyze trade-offs between the yield and the ecological state of the forest. The authors combined a rain forest growth model with MCDA for the first time. They evaluated the scenarios with the help of the multi-attribute value theory (MAVT) which aggregated 18 (non-monetary) indicators in 4 criteria (yield, canopy opening, and coarse/fine species composition). The influence of changes within the scenarios (logging intensities etc.) on all four criteria was analyzed as a second step. This combination of methods can compare the long-term impact of management strategies considering economic and ecological benefits. In a different study, Huth et al. (2005) used an extension of the preference ranking organization method for enrichment evaluations (PROMETHEE) to evaluate simulated logging scenarios. The improvement of this study to the former one is the consideration of uncertainties in the indicator values. The authors conclude that the combination of growth and yield studies with MCDA can improve the decision quality because they reduce misjudgments and subjective errors. Nordstrom et al. (2013) combined scenario analysis and MCDA to evaluate continuous cover forestry which has developed as an alternative to even-aged forestry. The aggregation of subjective and objective modeling has been regarded as a great advantage. In the future, the combination of MCDA with optimization tools like forest growth models needs to be improved by considering participatory processes within the model. This can be relevant to increase the sustainability of forest management. 
Further applications of MCDA are found within decision support systems (DSS) which accentuate the preferences of the decision makers and enhance the quality of the whole process. Overviews of the variety of DSS which are available have been provided by several authors (Bjørndal et al. 2012; Hartl et al. 2013; Weintraub and Romero 2006). The decision process can be improved through the use of MCDA. However, Korosuo et al. (2011) reveal that only a few DSS are connected with MCDA methods. Lexer et al. (2005) developed the DSS decision support Dobrova (DSD v1.1s) for forest owners in Southern Austria. They designed a generic model that resembles the consultation procedure by providing all relevant information about forest management alternatives and allowing for the simulation of treatment programs. In this model, the decision maker has the opportunity to insert specific information about species, sites, or timber prices into the program. Korosuo et al. (2011) used the forest planning tool PlanWise that includes the MCDA module PlanEval. By this means, forest plans can be compared and evaluated by the decision maker in a structured and analytical way. With the use of this computer-based support, the consideration of several details and expert knowledge can improve the decision. However, the user needs to have prior knowledge of the program. Individual land owners can already make use of this software with the assistance of experts, but further improvements are needed to make these tools more user-friendly. A technique combining MCDA with forest ecosystem models (FEM) was also described by Wolfslehner and Seidl (2010). FEMs are based on quantitative mathematical scaling which is used to simulate ecological processes. A combination of FEM and MCDA can capture both ecological and social criteria and the trade-offs among them that are important for decision analysis. Indicators are used as decision criteria for operational management on the enterprise level (Wolfslehner and Seidl 2010).

To obtain preference information of different stakeholders and thus generate forest plans that integrate these preferences, it is also possible to combine discrete and continuous MCDA methods. Diaz-Balteiro et al. (2009a) used pairwise comparison matrices based on the AHP to include the preferences of several stakeholders within the goal programming (GP) approach which optimizes the forest management in two different forests in Spain. The main strength of this method is that forest management problems have been analyzed with the consideration of multiple criteria and multiple stakeholders. This approach could be improved 
with the connection to a spatial analysis technique to facilitate data visualization and spatial allocation.

To summarize, only a few studies applied hybrid methods using MCDA within a quantitative programming-based optimization approach. The combination of quantitative optimization and MCDA has several advantages such as the consideration of economic and ecological benefits and the possibility to evaluate decisions in a structured and analytical way. Although it is rarely done, the application can both integrate stakeholder preferences and uncertainties into the decision process. To improve this aspect, MCDA can be combined with optimization methods with single objective but constrained scenario outcomes. In this way, uncertainties could be integrated with the Monte Carlo Simulation (MCS) into quantitative optimization to achieve transparent scenarios (see Hartl et al. 2013) and stakeholder preferences can be considered subsequently by means of MCDA.

\section{Hybrid Methods for Spatial Decision Problems}

Many spatial decision problems such as harvest strategies or nature conservation plans require a combination of MCDA and GIS (Malczewski 2006). Incorporating MCDA into GIS-based techniques improves the structure of the decision process by facilitating immediate data visualization and extensive spatial analysis. The major benefit of this combination in comparison to conventional MCDA methods is the geographic component, which facilitates spatial allocation (Ozturk and Batuk 2011). Particularly for forest management planning, which requires the simultaneous consideration of several ES and different silvicultural treatments for many forest stands, the combination of MCDA and geographical data can be very useful. Detailed review articles of GIS-based MCDA methods were published by Greene et al. (2011) and Malczewski (2006). There have been several studies in the field of forest management that combine MCDA and spatial planning. Sheppard and Meitner (2005) applied MCDA and visualization for sustainable forest management with different stakeholder groups. Spatio-temporal forecast modeling was used to evaluate ecological and operational conditions. Sharma et al. (2012) combined forest fire risk modeling with AHP to include actual fire occurrences into the decision process. The identification and mapping of different management zones with GIS was used to develop a management plan for nature reserves in China. A MCDA approach in this spatial context 
supported the zoning of different areas (Zhang et al. 2013). Destan et al. (2013) predicted forest stand volumes with the application of MCDA and GIS to develop objective forest stand maps. A GIS-based MCDA has also been used by Uribe et al. (2014) to identify forest landscape restoration priorities.

As several authors have mentioned in their papers, GIS based MCDA methods need to be more accessible to the general public (Greene et al. 2011; Malczewski 2006). As a tool which is most often used for spatial planning, GIS is quite expensive and complicated for the casual user. Accordingly, many web-based GIS tools are being developed (Boroushaki and Malczewski 2010), such as the web-enabled ordered weighted averaging tool (OWA) (Rinner and Malczewski 2002) and the program participatory GIS (Boroushaki and Malczewski 2010). Furthermore, spatial inaccuracies can arise in addition to general uncertainties that occur in forest management planning and MCDA such as inventory errors, timber price fluctuations, natural hazards, and subjective judgments. The integration of sensitivity and uncertainty analyses is therefore very important for the further development of methods. MCDA-GIS applications will be interesting for future development. It is particularly useful to connect stakeholder preferences, multiple criteria, and the spatial allocation of ES and silvicultural treatments.

\section{Hybrid Approaches Based on Participatory or Strategic Planning}

Most MCDA methods are able to consider preferences of multiple stakeholders in the decision-making process. Mendoza and Martins (2006) give a broad overview of the way preferences have been taken into account in different MCDA applications. There are large differences between the moment of the stakeholder's intervention (a priori, interactively and posterior) and the number of stakeholders that are involved in the process. The examples illustrate that many MCDA applications involve only one decision maker. This can be changed with a combination of MCDA with strategic or participatory planning to better fulfill the differing needs and objectives right from the beginning.

\section{MCDA and Participatory Planning}

Pykalainen et al. (2007) combined voting methods (Borda count, cumulative voting) with a multi-criteria approval (MA) to classify decisions into one category and evaluate the 
alternatives. The interactive utility analysis (IUA) was applied to facilitate the process of natural resource planning. It includes the formulation of weights and sub-utility functions as well as the calculations of total utilities for the different alternatives. Voting and MA information collect ordinal preference information from several stakeholders, whereas IUA determines further details by using the interval scale and calculating the total utilities. The authors concluded that a complementary use of different methods is needed to support stakeholders and to facilitate the decision process. A weakness of this combination of voting methods with MA is the absent of uncertainty analysis, particularly concerning uncertain preferences of the decision makers.

Approaches combining GDM with MCDA are relatively new in the field of forest planning (Diaz-Balteiro and Romero 2008). It gained importance in the 1990s after the UN Conference on Environment and Development in Rio (UNCED 1992). GDM can solve multi-stakeholder problems by including opinions, experiences, and knowledge into a decision process. The main challenge is resolving conflicts of different objectives and preferences (Groselj and Zadnik Stirn 2013). In a traditional MCDA method, one decision maker could be included. MCDA applications can be used within these qualitative GDM methods to connect the preferences of several stakeholders with the evaluation of multiple criteria and alternatives. Nordstrom et al. (2010) conducted a case study of a participatory planning process in Northern Sweden. In the first step, a stakeholder analysis was carried out to identify the relevant stakeholders and quantify the extent of their participation in the decision process. The next measure was structuring of the decision problem, followed by generation of a discrete number of alternatives. Preferences were elicited from every stakeholder for each criterion using the pairwise comparison procedure of the AHP, so that preferences could be combined. In the final step, alternatives were ranked.

Extensive stakeholder analyses might sometimes be difficult to conduct, and therefore, become a weakness of the approach. The participation process of multiple stakeholders needs to be simplified in the further development of decision methods. However, combining MCDA with participatory planning can be useful to comprehensively analyze stakeholder preferences and connect them to the evaluation of multiple criteria. 


\section{MCDA and Strategic Planning}

As Kloeze et al. (1980, p. 10) reveal, "strategic planning is often considered as a rather systematic process of actions in the determination of long-range objectives'. The SWOT method is a tool that analyzes internal and external environments for the strategic planning process. It can be used as a basis for strategy formulation (Kurttila et al. 2000). The utilization of SWOT is based on a qualitative examination of factors, which often makes it superficial (Kangas et al. 2001d). In A'WOT, SWOT analysis is combined with the AHP to make the whole process more analytical. In this way, factors of the SWOT framework are more easily compared. The AHP adds quantitative information to the analysis and also incorporates the preferences of the decision makers (Kangas et al. 2001d).

The first applications of A'WOT in forest management have been conducted by Kurtilla et al. (2000) and Kangas et al. (2001d). Also Groselj and Zadnik Stirn (2013) performed a SWOT analysis with several stakeholders to combine the results with the AHP developing the optimal management strategy for a forest. In this way, all alternatives can be compared according to all SWOT factors. Various other operations such as scenario planning and statistical analyses can be based on the SWOT approach in order to improve the decision process (Leskinen et al. 2006). Synergies between scenario planning and MCDA can lead to considerable advantages. Well-structured scenarios could, for example, reduce uncertainties and risks (Stewart et al. 2013). By this means, SWOT analysis can be used more efficiently. Overall, the combination of MCDA with strategic planning is useful to comprise several aspects of a decision problem.

\section{Overview of Classical Multi-criteria Decision Approaches}

Decision making can be seen as a multilayered process that begins with structuring a problem and ends with the selection of the best alternative (Kangas 1992a). Every decision we make requires the consideration of multiple factors and criteria. In a MCDA, a finite number of predefined or an infinite set of alternatives are generally evaluated based on a set of several criteria (Perman 2011) that often comprise ES. These ES need to be included for the promotion of sustainable development, particularly if a perspective beyond the enterprise level is taken, for example in landscape or national level planning. Some studies suggested the inclusion of ES or environmental damage via economic valuation methods for non-market 
goods and services (Carson 2012; Costanza et al. 1997). However, economic valuation of ES often does not reveal convincing results and have been criticized due to their insufficient validity and reliability (Hausman 2012). For this reason, MCDA is widely used as an alternative decision aid in natural resource management, because different criteria arising from economic, environmental, and social sources can be included in a MCDA (DiazBalteiro and Romero 2008). In contrast, economic valuation methods typically indicate their results in monetary units. According to Pagiola et al. (2004), this is a matter of convenience - to facilitate the comparison of ES that have non-market values. MCDA helps to structure the decision problem and to create a transparent process which in the end leads to a justifiable and explainable decision (Belton and Stewart 2002). In view of the many advantages mentioned above, the further use and development of MCDA methods will be important in the future. Especially aggregating MCDA methods and other decision-making techniques can be an important field of research to improve decision making. For this reason, we want to give a short overview of existing classical methods with relevant examples in forest management planning. References of studies are arranged firstly according to the type of application and secondly according to the name of the first author. MCDA methods can be subdivided into two major categories-discrete and continuous. While discrete methods classify a finite number of alternatives based on rankings or weightings, continuous methods define an infinite number of alternatives through the use of mathematical functions (Kangas et al. 2008; Vassilev et al. 2005).

\section{Discrete Methods}

Discrete methods of MCDA are based on the concept of modeling preferences. Here a finite number of alternatives are considered. Discrete methods include outranking approaches, utility-based methods as well as the AHP.

\section{Outranking Methods}

Outranking methods, such as the PROMETHEE, the elimination and choice translating reality (ELECTRE), and the technique for order of preference by similarity to ideal solution (TOPSIS) apply pairwise comparisons of alternatives. They have the ability to comprise ordinal and descriptive information (Kangas et al. 2001a). By using outranking methods, the decision maker can estimate the order of his/her preferences among the alternatives available, 
based on only a few assumptions (Kangas and Kangas 2005). Therefore, these methods do not require complete preference data, as is the case with other approaches, such as the AHP. Their weakness, however, is that the results they provide are often difficult to understand and interpret (Kangas et al. 2001a). With the application of PROMETHEE, the decision maker considers deviations between two alternatives according to his/her preferences for the individual criteria (Brans et al. 1986). The original PROMETHEE method has been altered several times (to PROMETHEE II-III) where interval rankings were included, and to PROMETHEE IV-VI with other modifications (Brans and Mareschal 2005). A detailed review of PROMETHEE methodologies and applications was published by Behzadian et al. (2010). Different authors such as Fontana et al. (2013), Jactel et al. (2012), and Palma et al. (2007) applied PROMETHEE in recent research studies to rank forest management alternatives. The PROMETHEE method is user-friendly and therefore frequently applied in natural resource management but it also has its limitations. It can only be applied if the decision maker can define a preference for each criterion and express the importance for his decision (de Keyser and Peeters 1996). The French ELECTRE method uses pairwise concordance and discordance tables to conduct a separate comparison of criteria for each alternative (Roy 1968). This method sometimes produces a set of leading alternatives rather than one preferred alternative. Therefore, ELECTRE is preferably used for decision problems with a large number of alternatives (Lootsma 1990). As with PROMETHEE, there have been several extensions of the ELECTRE approach. It has been frequently used as a decision support tool in forest management (Kangas et al. 2001c; Pauwels et al. 2007).

An alternative to the ELECTRE method is TOPSIS. This model evaluates the geometric distance and relative closeness of alternatives to the ideal and negative-ideal solutions with the use of Euclidean Distance. Here the best alternative is that which is closest to the ideal and furthest from the negative-ideal alternative (Triantaphyllou 2000). TOPSIS is easy to use and therefore popular in many fields of research. One drawback is that the Euclidean Distance does not include the correlation of attributes (Velasquez and Hester 2013).

\section{Utility-Based Methods}

Other discrete methods include applications which are based on value and utility such as the multi-attribute utility theory (MAUT), the MAVT as well as the simple multiattribute rating 
technique (SMART). These methods transform several criteria into units to feed into a dimensionless function that is used to maximize utility or value (Linkov and Bakr Ramadan 2004). Utility and value functions are based on comparisons between the alternatives. Utility and value are therefore scaled between 0 and 1 , and the sum for each alternative is calculated (Kangas et al. 2008). MAUT is certainly the most influential method among those mentioned in this section. It is based on the conventional utility theory and considers the importance of multiple attributes and their trade-offs. Keeney and Raiffa (1976) provide a comprehensive review of the history and background of MAUT. MAUT was applied in a number of studies to evaluate forest management strategies (Ananda and Herath 2005; Bell 1975). The heuristic optimization method HERO can also be used to estimate and maximize the utility function. The application deals with multiple objectives and stakeholder preferences, and combines the efficiency of numerical optimization (Kangas et al. 2001e). As a closely related theory to MAUT, MAVT is based on the identification of a value function. MAUT has an advantage over MAVT in that it includes both uncertainties and the risk preferences of the decision maker (Kangas et al. 2008). Due to the high amount of required data, the method of MAUT is not suitable for every kind of decision problem but for problems that contain uncertainty and provide enough of the required data (Velasquez and Hester 2013). SMART, which is based on MAUT, uses additive models that are generally applied to the decision hierarchy. Criteria are directly rated with numerical values, according to the decision maker's preferences (von Winterfeldt and Edwards 1986). MAUT requires more effort than SMART because the utility probabilities have to be scaled for each criterion and alternative (Brugha 2004).

\section{Analytical Hierarchy Process (AHP)}

Similarly to MAUT, the AHP integrates various aspects of the decision problem into one single objective function. The management alternative with the greatest value of the objective function can be selected (Linkov et al. 2004). The AHP uses pairwise comparisons and expert judgments to capture qualitative and intangible criteria and derive priorities. Judgments are quantified on a scale from 1 to 9, and criteria and alternatives are placed in a hierarchical structure to be comprehensively analyzed (Saaty 1990). Many researchers in the forestry sector use the AHP because of its interesting mathematical characteristics and the ease of its application (Kangas 1992b; Leskinen 2007). Also the ability of the AHP to incorporate 
subjective preferences and to help group decisions is seen as beneficial (Schmoldt and Mendoza 2001). Khadka and Vacik (2012), for example, used the AHP evaluating different management strategies in a community forest. One disadvantage is that the AHP is not able to carry out in-depth analyses (Kangas et al. 2008). In contrast to the AHP, its extension, the analytical network process (ANP) allows interdependencies and feedbacks among the decision elements to create a decision network (Gorener 2012). Ghajar and Najafi (2012) evaluated harvesting operations with the help of the ANP. The network structure provides a robust framework to integrate all variables in the decision model.

\section{Continuous Methods}

Methods are considered to be continuous when they find the preferred option among an infinite set of alternatives (Malczewski 1999). For the application of GP, which is a modification of the optimization technique linear programming (LP), a desirable target value for every single objective has to be defined (Field 1973). Complex decisions can be made objectively by minimizing the sum of unwanted deviations from the pre-defined targets (Tamiz et al. 1998). Furthermore, the a priori definition of targets for single objectives creates options for stakeholder participation. Various formulations of the achievement functions are possible. Normalized unwanted deviations may be weighted or a lexicographical approach may be used, where multiple objectives are prioritized and a sequence of linear programs is solved from high to low priorities. Also Chebyshev GP is available to solve multi-stakeholder problems. This approach minimizes the maximum unwanted deviation, rather than the sum of all deviations (Flavell 1976).

The main disadvantage of GP is that choosing targets and weights can be difficult for the decision maker because they could be inappropriate. In this way, reasonable goals and desirable solutions could be missed (Rivas-Da'valos et al. 2007). GP has been often applied to develop forest management plans. Diaz-Balteiro et al. (2009a) as well as Limaei et al. (2014) used GP to optimize the management of forest plantations. Diaz-Balteiro and Romero (2003) used a GP approach to identify harvest schedules with high levels of carbon storage and Gomez et al. (2006) applied GP determining the optimal harvest volume of a forest stand. While GP refers to multiple objective problems with target values, multi-objective programming (MOP) refers only to the class of multiple objective problems (McCarl and 
Spreen 1997). In forest planning, this technique can be used to generate a number of management plans when one objective cannot be improved without affecting other objectives (Nordstrom et al. 2013). Compromise programming (CP) is also known to solve forest management problems with multiple objectives (see Aldea et al. 2012; Diaz-Balteiro et al. 2014; Krcmar et al. 2005). CP minimizes the distance between the ideal and the achieved levels of objectives (Zeleny 1973). The difference between these methods lies in the definition of the distance functions (Krcmar et al. 2005). Often, alternatives to GP may be reformulated as GP problems. For example, it has been recommended that $\mathrm{CP}$ problems should be reformulated as GP problems to increase clarity and precision (Romero et al. 1998).

The data envelopment analysis (DEA), which is based on mathematical programming, can also be considered as a continuous MCDA method as it allows for simultaneous analysis of multiple inputs and outputs (Halog and Manik 2011). DEA has been applied in recent research studies to estimate the efficiency of forest management (e.g., Kao 2009; Limaei 2013; Shen et al. 2013).

In summary, different examples illustrate that continuous MCDA methods are widely used in the field of forest planning. As mentioned in "MCDA and quantitative optimization" section, the connection to qualitative methods could be useful to improve the practice of choosing targets and weights within the application.

\section{Challenges and Limitation of Multi-criteria Decision Analysis}

MCDA methods are increasingly used in modern forestry to support communicative and participatory approaches (Wolfslehner and Seidl 2010). Polatidis et al. (2006) specified a set of requirements for MCDA approaches used to aid decision making in environmental issues. They include, ease of comprehension, the ability to support many decision makers simultaneously, the inclusion of multiple criteria and alternatives, the consideration of uncertain information, and a low level of demand for time and money inputs. It is almost impossible to comply with all of these demands, although certain MCDA methods do get close to fulfilling at least some of these aspects. However, many MCDA techniques are rather complicated for the individual landowner, and therefore it is challenging to apply them at the regional level (Kangas et al. 2001e; Mendoza and Martins 2006), where ES should be 
addressed. In the following sections, we want to discuss the possibilities how to improve stakeholder participation, the consideration of uncertainty and the evaluation of trade-offs between ES. Hybrid methods respond better to these criteria by considering different features in one application.

\section{Stakeholder Participation}

In order to introduce expert knowledge and transparency into the decision process, stakeholder participation is seen as a fundamental cornerstone of all fields of sustainability assessment (Hahn and Knoke 2010). The formation of stakeholder opinions, experiences, and knowledge can be based on participatory planning (Groselj and Zadnik Stirn 2013). A participatory approach can enhance communication between stakeholders with different objectives, and therefore increase understanding (Doole and Pannell 2013; Lynam et al. 2007). In this way, modeling can be more effective, because decision makers are able to participate in the process and to recognize interdependencies and trade-offs between different criteria (Garcia-Barrios et al. 2008). Furthermore, the resulting increase in the ability of stakeholders to identify with the solution improves the potential for successful implementation of planned measures. As mentioned in "Hybrid approaches based on participatory or strategic planning" section, MCDA can be used within GDM methods to connect preferences of several decision makers. In this manner, stakeholder participation has been modeled in many studies.

Sandker et al. (2010) examined several interdisciplinary case studies of participatory modeling. The authors concluded that participation among different stakeholders is not a simple process but that these models "can be powerful tools to help stakeholders better understand the dynamics of landscapes and improve their decision making and investments in natural resource management" (Sandker et al. 2010, p. 12). Therefore, participatory modeling is certainly helpful for interdisciplinary decision making. The agent-based modeling (ABM) also allows for interactions between decision makers. $\mathrm{ABM}$ is a computerized simulation that explores quantitatively how the economy might react under different scenarios (Farmer and Foley 2009).

Another option for considering participation in a decision process is voting - $\mathrm{a}$ transparent process that the general public is familiar with. Vainikainen et al. (2008) examined several 
voting rules in forest planning situations. They concluded that the impact of different voters varies and that a fair process is required for the voting procedure to be effective. By all means, consultation with stakeholders throughout the modeling process can improve simulation models, and therefore influence decision making (Doole and Pannell 2013). As Sheppard and Meitner (2005) emphasize, the gap between participatory processes and complex decision support systems needs to be closed. There is a need for further studies integrating MCDA methods in participatory planning processes to improve the generation of alternatives and, in the end, to find the preferred management option.

\section{Consideration of Uncertainty}

Uncertainty in forest management planning can arise from different sources. According to Kangas et al. (2006, p. 114), following areas of uncertainty need to be taken into account: "(1) the errors in the basic forestry data (inventory and measurement errors), (2) the uncertainty of the future prices of timber, and (3) the uncertainty in predicting the forest development'. Hardly predictable events such as storms, heavy snow, fire, and insect attacks range under uncertainties related to forest planning. Also subjective judgments and uncertain preferences of the decision makers can cause uncertainties (Zarghami and Szidarovszky 2011), especially when multiple stakeholders are involved in the decision process.

Sensitivity analysis methods which are applicable in some MCDA techniques (e.g., AHP) can incorporate uncertainty in the criteria weights. However, there are limitations as only one input parameter can be varied at a time. With the use of distance-based uncertainty analysis, minimum modifications of the parameters (criteria weights and performance values) can be determined (Hyde 2006). In the MCDA method MAUT, probability distributions can represent the uncertainty. In this way, expected utilities are obtained for each alternative (Ananda and Herath 2005).

A widely applied approach in MCDA is the fuzzy set theory which involves the use of imprecise and uncertain data. A fuzzy set can be described as a class with "unsharp" boundaries. In this case, the transition from one characteristic to the other is gradual rather than abrupt (Gupta et al. 2000). The fuzzy set is based on a membership function (ranging between zero and one) which indicates the degree of truth by which certain data are accurate (Zadeh 1965). In an ecosystem context, most characteristics can be described as fuzzy, due to 
their complexity and many uncertainties in nature. These include, inter alia, the lack of information about interactions and changes within ecosystems. Linguistic scales, such as "low," "medium," and "high" are used to describe different criteria. These descriptive parameters can be transformed into fuzzy numbers which represent the membership function (Kangas et al. 2008). A triangular fuzzy number, for example, is a special class defined by three real numbers (Vahidnia et al. 2008). Conflicting objectives are evaluated based on their cumulative impacts. Those impacts are quantified by the product of the membership function and the relative importance (weight) of each of the attributes (Zadnik Stirn 2006).

Different MCDA methods can be fuzzified in order to integrate vague information into the decision process. The AHP is a method commonly used for fuzzification, because linguistic labels can be easily adopted into the procedure of pairwise comparisons (Durbach and Stewart 2012). In contrast, a fuzzy membership to a class can also be defined by grade or degree in a numerical way (Ducey and Larson 1999). As an example, Boyland et al. (2006) defined a fuzzy set for serial stages, where the degree of being member of a class or not is defined transitional in opposite to crisp and abrupt class boundaries. Thus, fuzzification can also be combined with optimization techniques such as LP (e.g., Boyland et al. 2006; Mendoza et al. 1993) and GP (Cheng 2013). The MCS is also beneficial to consider risks such as timber price volatilities and natural hazards in the evaluation of forest management alternatives. It can be used to compute annuities by means of up to 50,000 repetitions based on random sampling from MCS (see Roessiger et al. 2011).

In comparison to the amount of research that has been done in the field of MCDA, relatively little effort has been directed to uncertainty in decision problems up to now (Durbach and Stewart 2012). One certain reason for this is the high complexity of decision-making methods considering uncertainty (Kangas and Kangas 2004). Even though many studies do not incorporate uncertainty (Ananda and Herath 2009), there are a few good examples of recent studies in the field of forest planning. Kaya and Kahraman (2011) used the fuzzy AHP approach in urban forestation in Istanbul. Triantakonstantis et al. (2013) applied fuzzy set theory to indicate the influence of variables such as slope, distance to roads, and urban areas on forest land-use change. These studies indicate a future trend of increasing consideration of uncertainty in the decision-making process. 


\section{Evaluating Trade-Offs Between Ecosystem Services}

In the case of MCDA, the ability to compare highly dissimilar data is both an advantage and a weakness. While this comparison allows for a decision which potentially considers various heterogeneous objectives, it is the foundation for the difficulty in comparing dissimilar criteria at the same time. Due to this fact, the identification and analysis of trade-offs between environmental and economic criteria are particularly difficult (Polatidis et al. 2006). By changing a management practice, the landowner simultaneously affects the availability of multiple ES (Schwenk et al. 2012). ES can increase or decrease, and thereby affect other services, as they are usually linked (Robert 2013).

To analyze trade-offs and to make decisions more effective, levels and values of ES need to be quantified. In order to focus on forest management, different measures in the forest can change the provision of goods and services. Duncker et al. (2012) describe how forest management can affect trade-offs between ES (e.g., between biodiversity and production). A particular forest owner may implement management practices to produce a well-balanced combination of provisioning and regulating services. Generally, some ES may come at the cost of others. Trade-offs between different criteria could, for example, be represented through pay-off matrices that obtain the value for each criterion. A pay-off matrix can report the possibility of conflict between different criteria and objectives with the aim to compute optimal solutions (Andre' et al. 2010).

To facilitate the evaluation of ES and their trade-offs, MCDA methods can be applied. Seidl and Lexer (2013) employed a hybrid method with an assessment framework on the basis of MCDA, ecosystem modeling and stakeholder participation to reveal trade-offs between climate change impacts and adaptive capacity. Thus, uncertainties of future environmental conditions and societal demands on forests can be considered in forest planning. Fontana et al. (2013) compared different land-use types regarding their provision of ES with a comprehensive criteria assessment. Furthermore, participatory MCDA has been applied to address conflicting situations in forest planning involving different interest groups (e.g., Mustajoki et al. 2011; Nordstrom et al. 2010).

As Nelson et al. (2009) show, a landscape scale is necessary to reflect economic trade-offs between different scenarios to deliver ES. For example, reconciling food production and 
climate protection (e.g., through the preservation of natural forests) can only be addressed at a larger spatial scale (Wise et al. 2009). In landscape scale studies, forests are not analyzed as isolated options in landuse, but have to be seen as crucial parts of the landscapes (Paul and Knoke 2015). For this perspective, either various landscape scenarios may be pre-defined (e.g., Goldstein et al. 2012) or could be derived by mathematical programming techniques, for example, while including several strategies for forest preservation (Knoke et al. 2013). However, as an important second step, stakeholder preferences should be assessed and integrated to constitute a new variant of a hybrid approach in MCDA.

In conclusion, identifying trade-offs is important to understanding and balancing the advantages and disadvantages of different management scenarios (Raudsepp-Hearne et al. 2010). This is particularly useful for forest owners who wish to achieve multiple objectives with their management decisions (Butler et al. 2007).

\section{Methodological Improvements}

We have identified several challenges and limitations to the use of MCDA methods in forest management planning. In comparison to the sole use of MCDA, hybrid methods can be highly recommended for decision-making processes. To face future challenges, the improvement of hybrid methods is needed for the promotion of solutions which are efficient in the resource input, robust against uncertainty concerning their outcomes, and transparent for all stakeholders (Hahn and Knoke 2013). Up to now, a limited set of case studies apply hybrid methods in forest management planning. Besides, as shown in Table 1, there are only a few studies that consider stakeholder participation and uncertain data in one method.

Since hybrid methods can integrate many different aspects in one application, GIS mapping, optimization calculations, uncertainties, and stakeholder knowledge can be used as additional sources of information (Kangas et al. 2000). It is possible to simplify the evaluation of planning results with the application of different methods to the same process. However, increasingly complex methods can also turn out to be more expensive, more time consuming, and more difficult to understand for a large number of participants. As Mendoza and Martins (2006, p. 19) stated, MCDA should be made "more transparent, simple, and easily accessible', This is still a relevant requirement for future research, as it supports the development of participatory modeling, where all decision makers participate actively in the 
process. Furthermore, future decision processes will be characterized by stronger public awareness, more diverse demands of ES, and a quite severe uncertainty concerning future production, conditions, and demands. Thus, future development should focus on the simplification of MCDA and hybrid applications that integrate uncertain information and participatory planning.

To reinforce comprehensibility, interpretation, and transparency of decision support studies, we see much potential in hybrid methods combining scenario simulation with subsequent MCDA. Based on stakeholder integration by means of MCDA, the former scenarios may be revised. To ensure economic efficiency and transparency, we recommend scenario derivation by means of programming techniques, which are able to integrate uncertainties via MCS (see Hartl et al. 2013). MCDA methods could thus use optimized scenario outcomes as input for stakeholder participation. Their result can be played back to optimization models, promoting an iterative definition of objectives, assessment of their consequences and their subsequent weighting, and an optimized implementation. In this way, acceptable compromises between the landowner and the broad public can be identified relying on a set of efficient scenarios. So far, the majorities of optimization tools focus on market economic values and do not incorporate MCDA methods. Evaluating ES with no market value and their trade-offs are of special concern for the development of new methods. When a landowner integrates ES in the decision analysis, interdependences are often not considered. Trade-offs commonly occur and need to be analyzed for different management scenarios. For the evaluation of trade-offs, objective factors as well as subjective values need to be taken into account because they both have an influence on the development of various management scenarios (Nordstrom et al. 2013).

In the end, many different decision-making methods can be chosen for the evaluation of management alternatives. The choice of the appropriate method clearly depends on the decision maker's own views and objectives. However, the balance of ecological, social, and economic interests is significant to meet future requirements; and to comply with this objective, the further development of hybrid methods can be very valuable for decision making in forest management planning. 


\section{Acknowledgments}

The study is part of the two projects "Tree species diversity in Chilean forests - are naturalness and economics compatible?" funded by the Bauer Foundation within the "Stifterverband fur die Deutsche Wissenschaft" and "ARANGE - Advanced multifunctional forest management in European mountain ranges", (FP7-KBBE-2011-5) funded by the European Commission, FP7. The authors wish to thank Laura Carlson and John Guess for the language editing of the manuscript.

\section{References}

Aldea J, Martınez-Pena F, Diaz-Balteiro L (2012) Integration of fungal production in forest management using a multi-criteria method. Eur J Forest Res 131:1991-2003. doi:10.1007/s10342012-0649-y

Ananda J, Herath G (2005) Evaluating public risk preferences in forest land-use choices using multi-attribute utility theory. Ecol Econ 55:408-419. doi:10.1016/j.ecolecon.2004.12.015

Ananda J, Herath G (2009) A critical review of multi-criteria decision making methods with special reference to forest management and planning. Ecol Econ 68:2535-2548. doi:10.1016/j.ecolecon. 2009.05.010

Andre’ FJ, Cardenete MA, Romero C (2010) Designing public policies.

An approach based on multi-criteria analysis and computable general equilibrium modeling. Springer, Berlin, p 642

Behzadian M, Kazemzadeh R, Albadvi A, Aghdasi M (2010) PROMETHEE: a comprehensive literature review on methodologies and applications. Eur J Oper Res 200:198-215. doi:10.1016/j.ejor.2009. 01.021

Bell D (1975) A decision analysis of objectives for a forest pest problem. International Institute for Applied Systems Analysis, Laxenburg

Belton V, Stewart T (2002) Multiple criteria decision analysis. An integrated approach. Kluwer Academic Publishers, Boston

Bjørndal T, Herrero I, Newman A, Romero C, Weintraub A (2012) Operations research in the natural resource industry. Int Trans Oper Res 19:39-62. doi:10.1111/j.14753995.2010.00800.x

Boggia A, Cortina C (2010) Measuring sustainable development using a multi-criteria model: a case study. JEMA 91:2301-2306. doi:10.1016/j.jenvman.2010.06.009

Boroushaki S, Malczewski J (2010) ParticipatoryGIS: a web-based collaborative GIS and multicriteria decision analysis. Urisa 22:23-32 
Boyland M, Nelson J, Bunnell FL, D'Eon RG (2006) An application of fuzzy set theory for seral-class constraints in forest planning models. Forest Ecol Manag 223:395-402. doi:10.1016/j.foreco. 2005.12.001

Brans J, Mareschal B (2005) PROMETHEE methods. In: Figueira J, Greco S, Ehrgott M (eds) Multiple criteria decision analysis: state of the art surveys. Springer, Boston, pp 163-196

Brans J, Vincke P, Mareschal B (1986) How to select and how to rank projects: the Promethee method. Eur J Oper Res 24:228-238. doi:10.1016/0377-2217(86)90044-5

Brugha CM (2004) Phased multicriteria preference finding. Eur J Oper Res 158:308-316. doi:10.1016/j.ejor.2003.06.006

Butler B, Tyrell M, Feinberg G, VanManen S, Wiseman L, Wallinger S (2007) Understanding and reaching family forest owners: lessons from social marketing research. J Forest 105:348-357

Carson RT (2012) Contingent valuation: a practical alternative when prices aren't available. J Econ Perspect 26:27-42. doi:10.1257/ jep.26.4.27

Cheng H (2013) A satisficing method for fuzzy goal programming problems with different importance and priorities. Qual Quant 47:485-498. doi:10.1007/s11135-011-9531-0

Costanza R, d'Arge R, de Groot R, Farber S, Grasso M, Hannon B et al (1997) The value of the world's ecosystem services and natural capital. Nature 387:253-260. doi: $10.1038 / 387253 \mathrm{a} 0$

de Keyser W, Peeters P (1996) A note on the use of PROMETHEE multicriteria methods. Eur J Oper Res 89:457-461

Destan S, Yilmaz O, Sahin A (2013) Making objective forest stand maps of mixed managed forest with spatial interpolation and multi-criteria decision analysis. iForest 6:268277. doi:10.3832/ ifor0099-006

Diaz-Balteiro L, Romero C (2003) Forest management optimisation models when carbon captured is considered: a goal programming approach. Forest Ecol Manag 174:447457. doi:10.1016/S03781127(02)00075-0

Diaz-Balteiro L, Romero C (2008) Making forestry decisions with multiple criteria: a review and an assessment. Forest Ecol Manag 255:3222-3241. doi:10.1016/j.foreco.2008.01.038

Diaz-Balteiro L, Bertomeu M, Bertomeu M (2009a) Optimal harvest scheduling in eucalyptus plantations. Forest Policy Econ 11:548-554. doi:10.1016/j.forpol.2009.07.005

Diaz-Balteiro L, Gonzalez-Pachon J, Romero C (2009b) Forest management with multiple criteria and multiple stakeholders: an application to two public forests in Spain. Scan J For Res 24:87-93. doi:10.1080/02827580802687440

Diaz-Balteiro L, Martell DL, Romero C, Weintraub A (2014) The optimal rotation of a flammable forest stand when both carbon sequestration and timber are valued: a multi-criteria approach. Nat Hazards 72:375-387. doi:10.1007/s11069-013-1013-3 
Doole GJ, Pannell DJ (2013) A process for the development and application of simulation models in applied economics. Aust J Agr Res Econ 57:79-103. doi:10.1111/j.14678489.2012.00607.x

Ducey MJ, Larson BC (1999) A fuzzy set approach to the problem of sustainability. Forest Ecol Manag 115:29-40. doi:10.1016/ S0378-1127(98)00433-2

Duncker PS, Raulund-Rasmussen K, Gundersen P, Katzensteiner K, de Jong J, Ravn HP et al (2012) How forest management affects ecosystem services, including timber production and economic return: synergies and trade-offs. Ecol and Soc 17:50. doi:10. 5751/ES-05066-170450

Durbach IN, Stewart TJ (2012) Modeling uncertainty in multi-criteria decision analysis. Eur J Oper Res 223:1-14. doi:10.1016/j.ejor. 2012.04.038

Farmer JD, Foley D (2009) The economy needs agent-based modelling. Nature 460:685-686. doi:10.1038/460685a

Feizizadeh B, Blaschke T (2013) GIS-multicriteria decision analysis for landslide susceptibility mapping: comparing three methods for the Urmia lake basin, Iran. Nat Hazards 65:2105-2128. doi:10.1007/s11069-012-0463-3

Field D (1973) Goal programming for forest management. J Forest 19:125-135

Flavell RB (1976) A new goal programming formulation. Omega 4:731-732. doi:10.1016/0305-0483(76)90099-2

Fontana V, Radtke A, Bossi Fedrigotti V, Tappeiner U, Tasser E, Zerbe S, Buchholz T (2013) Comparing land-use alternatives: using the ecosystem services concept to define a multi-criteria decision analysis. Ecol Econ 93:128-136. doi:10.1016/j.ecole con.2013.05.007

Garc'1a-Barrios L, Speelman E, Pimm M (2008) An educational simulation tool for negotiating sustainable natural resource management strategies among stakeholders with conflicting interests. Ecol Model 210:115-126

Ghajar I, Najafi A (2012) Evaluation of harvesting methods for sustainable forest management (SFM) using the analytical network process (ANP). Forest Policy Econ 21:81-91. doi:10. 1016/j.forpol.2012.01.003

Goldstein JH, Caldarone G, Duarte TK, Ennaanay D, Hannahs N, Mendoza G et al (2012) Integrating ecosystem-service tradeoffs into land-use decisions. Proc Natl Acad Sci 109:7565-7570. doi:10.1073/pnas.1201040109

Go'mez T, Herna'ndez M, Leo' n M, Caballero R (2006) A forest planning problem solved via a linear fractional goal programming model. Forest Ecol Manag 227:79-88. doi:10.1016/j. foreco.2006.02.012

Go“rener A (2012) Comparing AHP and ANP: an application of strategic decisions making in a manufacturing company. Int J Bus Soc Sci 3:194-208

Greene R, Devillers R, Luther JE, Eddy BG (2011) GIS-based multiple-criteria decision analysis. Geogr Comp 5:412-432. doi:10.1111/j.1749-8198.2011.00431.x 
Groselj P, Zadnik Stirn L (2013) Between compromise and consensus in group decisions in forest management. $S^{\sim}$ umar list 7-8:403-410

Gupta A, Harboe R, Tabucanon M (2000) Fuzzy multiple-criteria decision making for crop area planning in Narmada river basin. Agr Syst 63:1-18

Hahn A, Knoke T (2010) Sustainable development and sustainable forestry: analogies, differences, and the role of flexibility. Eur J Forest Res 129:787-801

Hahn A, Knoke T (2013) Angebot, Nachfrage und Nachhaltigkeit im Wald. Holz-Zentralblatt 139:530-531

Halog A, Manik Y (2011) Advancing integrated systems modelling framework for life cycle sustainability assessment. Sustainability 3:469-499. doi:10.3390/su3020469

Hartl F, Hahn A, Knoke T (2013) Risk-sensitive planning support for forest enterprises: the YAFO model. Comput Electr Agr 94:58-70

Hausman J (2012) Contingent valuation: from Dubious to hopeless.

J Econ Perspect 26:43-56. doi:10.1257/jep.26.4.43

Herva M, Roca E (2013) Review of combined approaches and multicriteria analysis for corporate environmental evaluation. J Clean Prod 39:355-371. doi:10.1016/j.jclepro.2012.07.058

Hjorts $\varnothing \mathrm{CN}$ (2004) Enhancing public participation in natural resource management using Soft OR - an application of strategic option development and analysis in tactical forest planning. Eur J Oper Res 152:667-683. doi:10.1016/S0377-2217(03)00065-1

Huth A, Drechsler M, Ko“hler P (2004) Multicriteria evaluation of simulated logging scenarios in a tropical rain forest. JEMA 71:321-333. doi:10.1016/j.jenvman.2004.03.008

Huth A, Drechsler M, Ko“hler P (2005) Using multicriteria decision analysis and a forest growth model to assess impacts of tree harvesting in Dipterocarp lowland rain forests. Forest Ecol Manag 207:215-232. doi:10.1016/j.foreco.2004.10.028

Hyde KM (2006) Uncertainty analysis methods for multi-criteria decision analysis. School of Civil and Environmental Engineering, University of Adelaide, Adelaide

Jactel H, Branco M, Duncker P, Gardiner B, Grodzki W, Langstrom B et al (2012) A multicriteria risk analysis to evaluate impacts of forest management alternatives on forest health in Europe. Ecol and Soc 17:52. doi:10.5751/ES-04897-170452

Kangas J (1992a) Metsiko“n uudistamisketjun valinta-monitavoitteiseen hyo“tyteoriaan perustuva pa"a"to"sanalyysimalli. Summary: Choosing the regeneration chain in a forest stand: a decision analysis model based on multi-attribute utility theory. University of Joensuu, Joensuu

Kangas J (1992b) Multiple-use planning of forest resources by using the analytic hierarchy process. Scan J For Res 7:259-268. doi:10.1080/02827589209382718

Kangas J (1996) A participatory approach to tactical forest planning. Finnish society of forest planning; Finnish Forest Research Institute, Helsinki. Acta For Fenn 251 
Kangas AS, Kangas J (2004) Probability, possibility and evidence: approaches to consider risk and uncertainty in forestry decision analysis. Forest Policy Econ 6:169-188. doi:10.1016/S1389 9341(02)00083-7

Kangas J, Kangas A (2005) Multiple criteria decision support in forest management - the approach, methods applied, and experiences gained. Forest Ecol Manag 207:133-143. doi:10.1016/j.foreco. 2004.10.023

Kangas J, Store R, Leskinen P, Mehtatalo L (2000) Improving the quality of landscape ecological forest planning by utilizing advanced decision support tools. Forest Ecol Manag 132:157-171

Kangas A, Kangas J, Pykalainen J (2001a) Outranking methods as tools in strategic natural resources planning. Silva Fenn 35:215-227

Kangas J, Hyto“nen LA, Loikkanen T (2001b) Integrating the AHP and HERO into process of participatory natural resources planning. In: Schmoldt DL, Kangas J, Mendoza G, Pesonen $M$ (eds) The analytic hierarchy process in natural resource and environmental decision making. Kluwer Academic Publishers, Dordrecht, pp 131147

Kangas J, Kangas A, Leskinen P, Pyka“läinen J (2001c) MCDM methods in strategic planning of forestry on state-owned lands in Finland: applications and experiences. $\mathbf{J}$ Multi Crit Decis Anal 10:257-271. doi:10.1002/mcda.306

Kangas J, Pesonen M, Kurttila M, Kajanus M (2001) A'WOT: integrating the AHP with SWOT analysis. In: Dellman K (ed) Proceedings of the sixth international symposium on the analytic hierarchy process ISAHP 2001. Kursaal Bern, 2-4 Aug, BerneSwitzerland pp 189-199

Kangas J, Pukkala T, Kangas A (2001e) HERO: heuristic optimisation for multi-criteria forestry decision analysis. In: Schmoldt DL, Kangas J, Mendoza G, Pesonen M (eds) The analytic hierarchy process in natural resource and environmental decision making. Kluwer Academic Publishers, Dordrecht, pp 51-66

Kangas A, Kangas J, Lahdelma R, Salminen P (2006) Using SMAA-2 method with dependent uncertainties for strategic forest planning. Forest Policy Econ 9:113-125. doi:10.1016/j.forpol.2005. 03.012

Kangas A, Kangas J, Kurttila M (2008) Decision support for forest management. Springer, Dordrecht

Kao C (2009) Efficiency measurement for parallel production systems. Eur J Oper Res 196:1107-1112. doi:10.1016/j.ejor. 2008.04.020

Kaya T, Kahraman C (2011) Fuzzy multiple criteria forestry decision making based on an integrated VIKOR and AHP approach. Expert Syst Appl 38:7326-7333. doi:10.1016/j.eswa.2010.12.003

Keeney R, Raiffa H (1976) Decisions with multiple objectives. preferences and value tradeoffs. Wiley, New York

Khadka C, Vacik H (2012) Use of multi-criteria analysis (MCA) for supporting community forest management. iForest 5:60-71. doi:10.3832/ifor0608-009 
Khadka C, Hujala T, Wolfslehner B, Vacik H (2013) Problem structuring in participatory forest planning. Forest Policy Econ 26:1-11. doi:10.1016/j.forpol.2012.09.008

Kloeze H, Molenkamp A, Roelofs F (1980) Strategic planning and participation: a contradiction in terms? Long Range Plann 13:10-20. doi:10.1016/00246301(80)90098-9

Knoke T, Calvas B, Ochoa Moreno WS, Onyekwelu JC, Griess VC (2013) Food production and climate protection - what abandoned lands can do to preserve natural forests. Global Environ Chang 23:1064-1072. doi:10.1016/j.gloenvcha.2013.07.004

Korosuo A, Wikstro“m P, O” hman K, Eriksson LO (2011) An

integrated MCDA software application for forest planning: a case study in southwestern Sweden. Math Comput For Nat Res Sci 3:75-86

Krcmar E, van Kooten GC, Vertinsky I (2005) Managing forest and marginal agricultural land for multiple tradeoffs: compromising on economic, carbon and structural diversity objectives. Ecol Model 185:451-468. doi:10.1016/j.ecolmodel.2004.12.014

Kurttila M, Pesonen M, Kangas J, Kajanus M (2000) Utilizing the analytic hierarchy process AHP in SWOT analysis a hybrid method and its application to a forest-certification case. Forest Policy Econ 1:41-52

Leskinen P (2007) Comparison of alternative scoring techniques when assessing decision maker's multi-objective preferences in natural resource management. JEMA 85:363370. doi:10.1016/j. jenvman.2006.10.003

Leskinen L, Leskinen P, Kurttila M, Kangas J, Kajanus M (2006) Adapting modern strategic decision support tools in the participatory strategy process - a case study of a forest research station. Forest Policy Econ 8:267-278. doi:10.1016/j.forpol. 2004.06.007

Lexer M, Vacik H, Palmetzhofer D, Oitzinger G (2005) A decision support tool to improve forestry extension services for small private landowners in southern Austria. Comput Electr Agr 49:81-102. doi:10.1016/j.compag.2005.02.004

Limaei SM (2013) Efficiency of Iranian forest industry based on DEA models. J For Res 24:759-765. doi:10.1007/s11676-013-0371-8

Limaei SM, Kouhi MS, Sharaji TR (2014) Goal programming approach for sustainable forest management (case study in Iranian Caspian forests). J For Res 25:429-435. doi:10.1007/ s11676-014-0472-z

Linkov I, Bakr Ramadan A (eds) (2004) Comparative risk assessment and environmental decision making., NATO science series. Series IV, Earth and environmental sciencesKluwer Academic Publishers, Dordrecht, p 38

Linkov I, Seager T, Kiker G, Bridges T (2004) Multi-criteria decision analysis: a framework for structuring remedial decisions at contaminated sites. In: Linkov I, Bakr Ramadan A (eds) Comparative risk assessment and environmental decision making, vol 38. NATO science series. Series IV, Earth and environmental sciencesKluwer Academic Publishers, Dordrecht, pp 15-54 
Lootsma FA (1990) The French and the American school in multicriteria decision analysis. Oper Res 24:380-388

Lynam T, de Jong W, Sheil D, Kusumanto T, Evans K (2007) A review of tools for incorporating community knowledge, preferences, and values into decision making in natural resources management. http://www.ecologyandsociety.org/vol12/iss1/art5/. Accessed 14 Aug 2013

Malczewski J (1999) GIS and multicriteria decision analysis. Wiley, New York

Malczewski J (2006) GIS-based multicriteria decision analysis: a survey of the literature. Int J Geogr Inf Syst 20:703-726. doi:10. 1080/13658810600661508

McCarl BA, Spreen TH (1997) Applied mathematical programming using algebraic systems. http://agecon2.tamu.edu/people/faculty/ mccarl-bruce/books.htm. Accessed 14 Aug 2013

MEA (2005) Ecosystems and human well-being: synthesis. A report of the millennium ecosystem assessment. Island Press, Washington Mendoza G, Martins H (2006) Multi-criteria decision analysis in natural resource management: a critical review of methods and

new modelling paradigms. Forest Ecol Manag 230:1-22. doi:10. 1016/j.foreco.2006.03.023

Mendoza GA, Prabhu R (2000) Development of a methodology for selecting criteria and indicators of sustainable forest management: a case study on participatory assessment. Environ Manage 26:659-673. doi:10.1007/s002670010123

Mendoza GA, Bruce Bare B, Zhou Z (1993) A fuzzy multiple objective linear programming approach to forest planning under uncertainty. Agr Syst 41:257-274. doi:10.1016/0308-521X(93)90003-K

Mendoza G, Macoun P, Prabhu R, Sukadri D, Purnomo H, Hartanto H (1999) Guidelines for applying multi-criteria analysis to the assessment of criteria and indicators, vol 9., The Criteria \& indicators toolbox seriesCenter for International Forestry Research, Jakarta

Mustajoki J, Saarikoski H, Marttunen M, Ahtikoski A, Hallikainen V, Helle T et al (2011) Use of decision analysis interviews to support the sustainable use of the forests in Finnish Upper Lapland. J Environ Manage 92:1550-1563. doi:10.1016/j.jenv man.2011.01.007

Myllyviita T, Hujala T, Kangas A, Leskinen P (2011) Decision support in assessing the sustainable use of forests and other natural resources - a comparative review. Open For Sci J 4:24-41

Nelson E, Mendoza G, Regetz J, Polasky S, Tallis H, Cameron D et al (2009) Modeling multiple ecosystem services, biodiversity conservation, commodity production, and tradeoffs at landscape scales. Front Ecol Environ 7:4-11. doi:10.1890/080023

Nordstro“ m E, Eriksson L, O” hman K (2010) Integrating multiple criteria decision analysis in participatory forest planning:

experience from a case study in northern Sweden. Forest Policy Econ 12:562-574. doi:10.1016/j.forpol.2010.07.006 
Nordstro“ m E, Holmstro“m H, O” hman K (2013) Evaluating continuous cover forestry based on the forest owner's objectives by

combining scenario analysis and multiple criteria decision analysis. Silva Fenn. 47:1-22. doi:10.14214/sf.1046

Ozturk D, Batuk F (2011) Implementation of GIS-based mulicriteria decision analysis with VB in ArcGIS. Int J Infor Tech Dec Mak 10:1023-1042. doi:10.1142/S0219622011004695

Pagiola S, von Ritter K, Bishop J (2004) Assessing the economic value of ecosystem conservation. World Bank Environment Department, Washington

Palma J, Graves A, Burgess P, van der Werf W, Herzog F (2007) Integrating environmental and economic performance to assess modern silvoarable agroforestry in Europe. Ecol Econ 63:759-767. doi:10.1016/j.ecolecon.2007.01.011

Paul C, Knoke T (2015) Between land sharing and land sparing - what role remains for forest management and conservation? Int Forest Rev (in press)

Pauwels D, Lejeune P, Rondeux J (2007) A decision support system to simulate and compare silvicultural scenarios for pure evenaged larch stands. Ann For Sci 64:345-353. doi:10.1051/forest: 2007011

Perman R (2011) Natural resource and environmental economics, 4th edn. Pearson Addison Wesley, Harlow

Polatidis H, Haralambopoulos D, Munda G, Vreeker R (2006) Selecting an appropriate multicriteria decision analysis technique for renewable energy planning. Energy Source Part B 1:181-193. doi:10.1080/009083190881607

Pukkala T, Kangas J (1993) A heuristic optimization method for forest planning and decision making. Scan J For Res 8:560-570. doi:10.1080/02827589309382802

Pyka“läinen J, Hiltunen V, Leskinen P (2007) Complementary use of voting methods and interactive utility analysis in participatory strategic forest planning: experiences gained from western Finland. Can J For Res 37:853-865. doi:10.1139/X06-241

Raudsepp-Hearne C, Peterson G, Bennett E (2010) Ecosystem service bundles for analyzing tradeoffs in diverse landscapes. Proc Natl Acad Sci 107:5242-5247. doi:10.1073/pnas.0907284107

Rinner C, Malczewski J (2002) Web-enabled spatial decision analysis using ordered weighted averaging (OWA). J Geogr Syst 4:385-403. doi:10.1007/s 101090300095

Rivas-Da'valos F, Moreno-Goytia E, Gutie'rrez-Alcaraz G, TovarHerna'ndez J (2007) Evolutionary multi-objective optimization in power systems: state-of-the-art. In : IEEE Lausanne Power Tech, 2007. Lausanne, Switzerland. IEEE Service Center, Piscataway, 1-5 July 2007

Robert N (2013) Sustaining the supply of multiple ecosystem services. An analysis based on the simulation of the joint production of wood and non-wood goods in forests. Dissertation, Paris Tech, Nancy Cedex. French National Institute of Geographic and Forest Information (IGN) and Laboratory of Forest Economics 
Roessiger J, Griess VC, Knoke T (2011) May risk aversion lead to near-natural forestry? A simulation study. Forestry 84:527-537. doi:10.1093/forestry/cpr017

Romero C, Tamiz M, Jones DF (1998) Goal programming, compromise programming and reference point method formulations: linkages and utility interpretations. J Oper Res Soc 49:986-991. doi:10.1057/palgrave.jors.2600611

Roy B (1968) Classement et choix en pre'sence de points de vue multiples-La me'thode ELECTRE. RIRO 8:57-75

Saaty T (1990) The analytic hierarchy process. planning, priority setting, resource allocation, 2nd edn. RWS Publications, Pittsburgh

Sandker M, Campbell B, Ruiz-Pe'rez M, Sayer J, Cowling R, Kassa H, Knight A (2010) The role of participatory modeling in landscape approaches to reconcile conservation and development, 2. http://www.ecologyandso ciety.org/vol15/iss2/art13/. Accessed 14 Aug 2013

Sanon S, Hein T, Douven W, Winkler P (2012) Quantifying ecosystem service trade-offs: the case of an urban floodplain in Vienna, Austria. JEMA 111:159-172. doi:10.1016/j.jenvman. 2012.06.008

Schmoldt DL, Mendoza G (2001) Past developments and future directions for the AHP in natural resources. In: Schmoldt DL, Kangas J, Mendoza G, Pesonen M (eds) The analytic hierarchy

process in natural resource and environmental decision making. Kluwer Academic Publishers, Dordrecht, pp 289-305

Schwenk W, Donovan T, Keeton W, Nunery J (2012) Carbon storage, timber production, and biodiversity: comparing ecosystem services with multi-criteria decision analysis. Ecol Appl 22:1612-1627

Seidl R, Lexer MJ (2013) Forest management under climatic and social uncertainty: tradeoffs between reducing climate change impacts and fostering adaptive capacity. J Environ Manage 114:461-469. doi:10.1016/j.jenvman.2012.09.028

Sharma LK, Kanga S, Nathawat MS, Sinha S, Pandey PC (2012) Fuzzy AHP for forest fire risk modeling. Disaster Prevent Manag 21:160-171. doi:10.1108/09653561211219964

Shen J, Jing Z, Wen Y (2013) Measuring the true technical efficiency of farmers' forest management in Fujian, China: a three-stage dea analysis. Inf Technol J 12:86048608. doi:10.3923/itj.2013. 8604.8608

Sheppard SR, Meitner M (2005) Using multi-criteria analysis and visualisation for sustainable forest management planning with stakeholder groups. Forest Ecol Manag 207:171-187. doi:10. 1016/j.foreco.2004.10.032

Stewart TJ, French S, Rios J (2013) Integrating multicriteria decision analysis and scenario planning-review and extension. Omega 41:679-688. doi:10.1016/j.omega.2012.09.003 
Tamiz M, Jones D, Romero C (1998) Goal programming for decision making: an overview of the current state-of-the-art. Eur J Oper Res 111:569-581. doi:10.1016/S03772217(97)00317-2

Triantakonstantis DP, Kalivas DP, Kollias VJ (2013) Autologistic regression and multicriteria evaluation models for the prediction of forest expansion. New Forest 44:163-181. doi:10.1007/ s11056-012-9308-x

Triantaphyllou E (2000) Multi-criteria decision making methods. A comparative study. Kluwer Academic Publishers, Dordrecht

UNCED (1992) The non-legally binding authoritative statement of principles for a global consensus on the management, conservation and sustainable development of all types of forests. Report on the United Nations Conference on Environment and Dept. Rio de Janeiro

Uribe D, Geneletti D, del Castillo R, Orsi F (2014) Integrating stakeholder preferences and GIS-based multicriteria analysis to identify forest landscape restoration priorities. Sustainability 6:935-951. doi:10.3390/su6020935

Vahidnia M, Alesheikh A, Alimohammadi A, Bassiri A (2008) Fuzzy analytical hierarchy process in GIS application. Int Arch Photogramm Remote Sens Spat Inf Sci 37(B2):593-596

Vainikainen N, Kangas A, Kangas J (2008) Empirical study on voting power in participatory forest planning. JEMA 88:173-180. doi:10.1016/j.jenvman.2007.02.004

Vassilev V, Genova K, Vassileva M (2005) A brief survey of multicriteria decision making and software systems. Cybernet Inf Tech 5:3-13

Velasquez M, Hester PT (2013) An analysis of multi-criteria decision making methods. Int $\mathbf{J}$ Oper Res 10:56-66

von Winterfeldt D, Edwards W (1986) Decision analysis and behavioral research. Cambridge University Press, Cambridge

Weintraub A, Romero C (2006) Operations research models and the management of agricultural and forestry resources: a review and comparison. Interfaces 36:446-457. doi:10.1287/inte.1060.0222 Willis AJ (1997) The ecosystem: an evolving concept viewed

historically. Funct Ecol 11:268-271

Wise M, Calvin K, Thomson A, Clarke L, Bond-Lamberty B, Sands R et al (2009) Implications of Limiting $\mathrm{CO} 2$ concentrations for land use and energy. Science 324:1183-1186. doi:10.1126/ science.1168475

Wolfslehner B, Seidl R (2010) Harnessing ecosystem models and multicriteria decision analysis for the support of forest management. Environ Manag 46:850-861. doi:10.1007/s00267-009-9414-5

Wolfslehner B, Vacik H, Lexer MJ (2005) Application of the analytic network process in multi-criteria analysis of sustainable forest management. For Ecol Manag 207:157170. doi:10.1016/j. foreco.2004.10.025 
Wolfslehner B, Brüchert F, Fischbach J, Rammer W, Becker G, Lindner M, Lexer MJ (2012) Exploratory multi-criteria analysis in sustainability impact assessment of forest-wood chains: the example of a regional case study in Baden-Württemberg. Eur J Forest Res 131:47-56. doi:10.1007/s10342-011-0499-Z

Zadeh L (1965) Fuzzy sets. Inf Control 8:338-353

Zadnik Stirn L (2006) Integrating the fuzzy analytic hierarchy process with dynamic programming approach for determining the optimal forest management decisions. Ecol Model 194:296-305. doi:10. 1016/j.ecolmodel.2005.10.023

Zarghami M, Szidarovszky F (2011) Multicriteria analysis. Applications to water and environment management. Springer, Berlin

Zeleny M (1973) Compromise programming. In: Cochrane JL, Zeleny M (eds) Multiple criteria decision making, 1st edn. University of South Carolina Press, Columbia, pp 262-301

Zhang Z, Sherman R, Yang Z, Wu R, Wang W, Yin M et al (2013) Integrating a participatory process with a GIS-based multicriteria decision analysis for protected area zoning in China. J Nat Conserv 21:225-240. doi:10.1016/j.jnc.2012.12.006 